\title{
Erratum to: Is immunosenescence influenced by our lifetime "dose" of exercise?
}

\author{
James E. Turner
}

Published online: 17 May 2016

(C) Springer Science+Business Media Dordrecht 2016

\section{Erratum to: Biogerontology DOI 10.1007/s10522-016-9642-z}

In the published article, an error was made during the production process in the text under the subheading "Future research to robustly test the anti-immunosenescence effect of exercise" (see 14th page; final page numbers were not available at the time of publishing this erratum).

The text provides a description and summary of findings from a pilot study that is currently unpublished, but is accompanied by an in-text citation displayed as "Turner et al. 2016". The in-text citation should have been listed as "Turner et al. unpublished data".

Thus, the text in this section should read:

"Initial observations ( $n=5$ healthy well-trained males aged 20-26 years) indicate that the numbers and proportions of late-stage differentiated CD4+ and CD8 + T cells, measured 10 and $24 \mathrm{~h}$ after $60 \mathrm{~min}$ of treadmill running at $80 \% \dot{\mathrm{V}} \mathrm{O}_{2_{\text {max }}}$ are not substantially different from pre-exercise levels (Turner et al. unpublished data)."
The online version of the original article can be found under doi:10.1007/s10522-016-9642-z.

\section{J. E. Turner ( $\square)$}

Department for Health, University of Bath, Claverton

Down, Bath BA2 7AY, UK

e-mail: j.e.turner@bath.ac.uk 